\title{
The practical use of goal attainment scaling for people with acquired brain injury who receive cognitive rehabilitation
}

Citation for published version (APA):

Bouwens, S. F. M., van Heugten, C. M., \& Verhey, F. R. J. (2009). The practical use of goal attainment scaling for people with acquired brain injury who receive cognitive rehabilitation. Clinical Rehabilitation, 23(4), 310-320. https://doi.org/10.1177/0269215508101744

Document status and date:

Published: 01/01/2009

DOI:

10.1177/0269215508101744

Document Version:

Publisher's PDF, also known as Version of record

Document license:

Taverne

Please check the document version of this publication:

- A submitted manuscript is the version of the article upon submission and before peer-review. There can be important differences between the submitted version and the official published version of record.

People interested in the research are advised to contact the author for the final version of the publication, or visit the DOI to the publisher's website.

- The final author version and the galley proof are versions of the publication after peer review.

- The final published version features the final layout of the paper including the volume, issue and page numbers.

Link to publication

\footnotetext{
General rights rights.

- You may freely distribute the URL identifying the publication in the public portal. please follow below link for the End User Agreement:

www.umlib.nl/taverne-license

Take down policy

If you believe that this document breaches copyright please contact us at:

repository@maastrichtuniversity.nl

providing details and we will investigate your claim.
}

Copyright and moral rights for the publications made accessible in the public portal are retained by the authors and/or other copyright owners and it is a condition of accessing publications that users recognise and abide by the legal requirements associated with these

- Users may download and print one copy of any publication from the public portal for the purpose of private study or research.

- You may not further distribute the material or use it for any profit-making activity or commercial gain

If the publication is distributed under the terms of Article $25 \mathrm{fa}$ of the Dutch Copyright Act, indicated by the "Taverne" license above, 


\title{
The practical use of goal attainment scaling for people with acquired brain injury who receive cognitive rehabilitation
}

\begin{abstract}
Sharon FM Bouwens School for Mental Health and Neuroscience, Department of Psychiatry and Neuropsychology, Maastricht University, Caroline M van Heugten School for Mental Health and Neuroscience, Department of Psychiatry and Neuropsychology, Maastricht University, and Centre of Excellence in Rehabilitation Medicine and Rudolf Magnus Institute for Neurosciences, Utrecht and Frans RJ Verhey School for Mental Health and Neuroscience, Department of Psychiatry and Neuropsychology, Maastricht University, and University Hospital Maastricht, Maastricht, The Netherlands
\end{abstract}

Received 27th September 2008; returned for revisions 4th November 2008; revised manuscript accepted 5th November 2008.

Objective: To examine the feasibility of and clinical experiences with goal attainment scaling when used for the evaluation of cognitive rehabilitation in people with acquired brain injury.

Design: A prospective observational longitudinal study.

Setting: A 21-week cognitive rehabilitation programme and a cognitive programme with varying length in two different Dutch rehabilitation centres.

Subjects: Forty-eight consecutive patients with acquired brain injury enrolled during a 15-month period.

Interventions: Cognitive rehabilitation programme.

Main measure: Goal attainment scaling; the number of goals was counted; time to set goals was recorded; the number of different domains in which goals were set was counted; goal attainment scaling score was calculated at baseline, one week after the end of the cognitive rehabilitation programme and at six months follow-up; clinical experiences that could be useful for both clinical and research practice were recorded.

Results: The mean (SD) age of the patients was 46.1 (10.7) years; 29 (60\%) were male; 186 goals were set with a mean (SD) number of 4 (1) goals per patient. It was possible to set at least three realistic goals per patient within 30 minutes. Most goals were set in the cognitive domain (i.e. memory and attention), followed by the behavioural domain (i.e. fatigue and aggression).

Conclusion: It proved possible to set three goals within an acceptable time-frame, to involve patients in the goal-setting procedure, to set realistic goals, and to set goals within relevant domains. Based on clinical experiences, goal attainment scaling is less feasible for research when patients lack insight, or suffer from comorbidity or mood problems.

Address for correspondence: CM van Heugten, School for Mental Health and Neuroscience/Maastricht University, DOT 12, PO Box 616, 6200 MD Maastricht, The Netherlands. e-mail: C.vanHeugten@np.unimaas.nl 


\section{Introduction}

Acquired brain injury can lead not only to physical deficits, but also to deficits in cognition, emotion, behaviour and psychosocial functioning. ${ }^{1-3}$ After spontaneous recovery, most people with brain injury still experience problems in their daily lives, like forgetfulness, lack of initiative, anger and anxiety.

Cognitive rehabilitation is aimed at improving patients' ability to function in daily life. ${ }^{4}$ Cognitive rehabilitation is based on well-described principles, such as compensatory training to adapt to the presence of a cognitive deficit. ${ }^{3-6}$ As described by Ben-Yishay et al., ${ }^{7}$ the general goals of cognitive rehabilitation are: to improve the self-awareness of strengths and weaknesses; to improve coping and compensating skills; to improve personal organization, social skills and effectiveness, emotional and behavioural self-management, participation in social, work and leisure activities and health maintenance. It is important that these principles and general goals are in line with the personal needs and preferences of the patient. Goal attainment scaling is a method that takes these personal needs into account. ${ }^{8}$

Goal attainment scaling is a measurement method for programme evaluation in mental health centres ${ }^{9}$ that allows for both the individualization of patient goals according to the needs of each patient, and the standardization of measurement. ${ }^{10}$ Goal attainment scaling reflects actual improvement in a patient's functional ability ${ }^{11}$ and can be adapted to any level or domain of the International Classification of Functioning, Disability, and Health (ICF). ${ }^{12}$ Hence goal attainment scaling is a method that can be used to cover any aspect of illness.

Due to the increasing emphasis on a more client-centred approach in health care in general, goal attainment scaling has recently been used in patient groups with various disorders including brain injury. ${ }^{9}$ Measurement properties like reliability, validity and responsiveness of goal attainment scaling when used in people with brain injury who are receiving cognitive rehabilitation, were studied in advance and have proved promising. ${ }^{9,10,13-15}$ Bouwens et al. ${ }^{16}$ reviewed the literature on the applicability of goal attainment scaling in psychogeriatric patients with cognitive disorders. They found that the use of goal attainment scaling was feasible both with regard to the involvement of patient and/or caregiver in the goal-setting procedure as well as with regard to the possibility of implementing multiple domains in the goal-setting procedure. The feasibility of goal attainment scaling in people with acquired brain injury who receive cognitive rehabilitation is not well established, however, as the sample sizes of the above-mentioned studies were small, or the results were inconsistent and the clinical experiences were recorded insufficiently. Information about the usefulness of goal attainment scaling in this population is important since a method should not only depend on good psychometric value. As goal attainment scaling is a promising clinical method for interventions, its feasibility needs to be tested and clinical experiences with it in practice need to be examined.

Therefore, the aim of this study is to examine the feasibility of, and clinical experiences with goal attainment scaling when used for the evaluation of cognitive rehabilitation in people with acquired brain injury.

\section{Methods}

This study is based on patients with acquired brain injury who were referred to two ongoing cognitive rehabilitation programmes by neurologists, general practitioners and rehabilitation physicians. The programmes were provided by two Dutch rehabilitation centres, viz. rehabilitation centre Blixembosch in Eindhoven and rehabilitation centre Hoensbroeck in Hoensbroek. Both cognitive rehabilitation programmes were part of normal service delivery. Patients enrolled in the programmes between September 2006 and December 2007.

The criteria for referral to the programme are the following: patients have sustained an acquired brain injury at least three months earlier, patients are older than 18 years, the patient experiences cognitive, emotional and/or behavioural problems interfering with daily functioning for which information and advice and treatment are necessary to assure adaptation to these problems, the patient 


\section{SFM Bouwens et al.}

has sufficient insight in his or her own problems in order to benefit from a low frequent treatment intensity, communication in daily life is not hindered (the patient can read and write), the patients' social behaviour is adequate in order to function in a group programme, there are no treatment goals in the sensori-motor area of functioning (any more). Patients with primary psychological or psychiatric disorders, dementia or a whiplash trauma are excluded from the programme.

The aims of both cognitive rehabilitation programmes are the following: (1) to help the patient and caregivers to gain insight in the consequences of the brain damage; (2) to offer strategies to handle cognitive deficits in their daily life; (3) to learn social skills in order to live with the consequences; (4) to learn how to control emotional reactions; and (5) to enhance self-efficacy. With these aims, the impairments as such are not treated, but the patients and their caregivers learn to live with, manage, cope with and accept these consequences in order to maximize participation in society. The intensity of the programmes differed.

Goal attainment scaling is used as a method to measure level of attainment of individual goals. This method is described in Appendix 1. Table 1 shows an example of a goal attainment scaling follow-up guide. A neuropsychological test battery consisting of 12 neuropsychological tests was administered to identify the level of cognitive functioning. For this study, we present mean (SD) scores of five well-known neuropsychological tests of which adequate norms are available: the Auditory Verbal Learning Test (AVLT) ${ }^{17}$ to measure verbal episodic memory; part A of the Trail Making Test (TMT) ${ }^{18}$ to measure basal speed; the $\mathrm{D} 2^{19}$ to measure selective and sustained attention; the action plan test, the rule shift test, the zoo map test and the six element test of the Behavioural Assessment of Dysexecutive Syndrome (BADS) ${ }^{20}$ to measure executive functioning; and the matrices reasoning of the Wechsler Adult Intelligence Scale-III (WAIS-III) ${ }^{21}$ to measure general abstract reasoning. The level of everyday functioning was assessed via an interview with the patient and caregiver separately about 87 instrumental activities of daily life (IADL). For this study we used data about preparing a meal, shopping, telephone use and activities with regard to mail, appointments and finances. We counted the number of patients who had problems with these activities.

At baseline (one week before the start of the programme), a clinical researcher who was not involved in the cognitive rehabilitation programme, but who was familiar with the content of the programme, constructed goal attainment scaling follow-up guides for all patients, either at home or at the rehabilitation centre. The team members of the programme received a copy of

Table 1 An example of a goal attainment scaling follow-up guide of an adult brain-injured patient

\begin{tabular}{|c|c|c|c|}
\hline & \multicolumn{3}{|l|}{ Goal areas } \\
\hline & Dealing with impaired memory & $\begin{array}{l}\text { Acceptance of consequences } \\
\text { injury }\end{array}$ & Coping with aggression \\
\hline $\begin{array}{l}\text { Much less than } \\
\text { expected }(-2)\end{array}$ & $\begin{array}{l}\text { Poor short-term memory, no } \\
\text { use of memory aids }\end{array}$ & No acceptance of disease ${ }^{a}$ & $\begin{array}{l}\text { Becomes aggressive in all } \\
\text { situations of misunderstanding }\end{array}$ \\
\hline $\begin{array}{l}\text { Somewhat less than } \\
\text { expected }(-1)\end{array}$ & $\begin{array}{l}\text { Uses memory aids when } \\
\text { another person cues } \\
\text { to do so }{ }^{\mathrm{a}}\end{array}$ & $\begin{array}{l}\text { Received information on } \\
\text { coping strategies, but no } \\
\text { feeling of coping }\end{array}$ & $\begin{array}{l}\text { Becomes aggressive in almost } \\
\text { all situations of } \\
\text { misunderstanding }^{\text {a }}\end{array}$ \\
\hline Programme goal (0) & $\begin{array}{l}\text { Able to use memory aids with } \\
\text { external cue like watch }\end{array}$ & $\begin{array}{l}\text { Learned how to cope with } \\
\text { disease, but no full } \\
\text { acceptance }^{b}\end{array}$ & $\begin{array}{l}\text { Learned how to stay calm, } \\
\text { but does not succeed in } \\
\text { all situations }\end{array}$ \\
\hline $\begin{array}{l}\text { Somewhat better } \\
\text { than expected }(+1)\end{array}$ & $\begin{array}{l}\text { Able to use memory aids } \\
\text { spontaneously }\end{array}$ & Almost full acceptance & Rarely becomes aggressive ${ }^{b}$ \\
\hline $\begin{array}{l}\text { Much better than } \\
\text { expected }(+2)\end{array}$ & No need for memory aids & $100 \%$ acceptance of disease & $\begin{array}{l}\text { Never becomes aggressive } \\
\text { anymore }\end{array}$ \\
\hline
\end{tabular}

${ }^{a}$ Admission level.

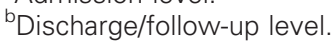


the goals so they knew what goals were set by each patient. At baseline the neuropsychological test battery was administered to all patients in a quiet testing room. The IADL interview was done with the patient and caregiver separately.

The time point that was set as the target for goal attainment was one week after the end of the programme. At six months follow-up, the level of attainment was measured again to see if patients remained at the same level as was attained one week after the end of the programme. If the caregiver was present during the goal-setting procedure and the caregiver was influencing the patient, the clinical researcher made it clear that the patient determined whether the goal was important or not. The clinical researcher scored the short-term level of attainment on the goal attainment scaling follow-up guide with the patient one week after the end of the programme. For practical reasons, the scoring of the level of attainment was done by phone. The researcher read out loud the descriptions for each level of attainment and asked the patient which description was applicable at time of measurement. At six months follow-up, the clinical researcher made a second phone call to score the level of attainment again. The ethics committee approved this procedure.

To investigate the feasibility of goal attainment scaling, the number of goals set was counted; time to set goals was recorded; the number of different domains in which goals were set was counted; goal attainment scaling scores were calculated at baseline, one week after the end of the cognitive rehabilitation programme and at six months follow-up; and clinical experiences that could be useful for both clinical and research practice were recorded, such as the possibility to involve the patient in the goal-setting procedure.

The standards of the feasibility aspects were based on Bouwens et al. ${ }^{16}$ :

(1) The number of goals was considered sufficient when at least three goals were set.

(2) The time required for setting the goals was considered good when it took a maximum of 30 minutes to construct a goal attainment scaling follow-up guide of at least three goals.
(3) Domains included in the goals had to cover at least two of the following general domains in order to be relevant: cognition, emotion and behaviour. As these three domains are the core focus of cognitive rehabilitation, they were self-evidently relevant to the method.

(4) The achievement of a mean goal attainment scaling score of $50(\mathrm{SD}=10$, range $40-60)$. The achievement of a mean goal attainment scaling score of 50 one week after the end of the programme is the criterion by which we judge if the goals overall had been realistic.

\section{Statistical analyses}

Descriptive statistics of the patient characteristics were given, the time required for setting the goals, and the number of goals were calculated. The total number of goals that was set per general domain and per specific domain as well as the number of general domains covered by the goals was calculated for the total group. Mean goal attainment scaling scores were performed per time of measurement.

Percentages were calculated for the number of goals for each level of attainment one week after the end of the programme and at six months follow-up. Independent-samples $T$-test was performed to analyse the difference between length of the rehabilitation programmes. Statistical analyses were performed with the Statistical Package for Social Sciences (version 16.0) (SPSS Inc, Chicago, IL, USA) with an alpha level set at 0.05 for all analyses.

\section{Results}

Forty-eight patients fulfilled the inclusion criteria for this study. Data at baseline were complete for all 48 patients; one week after the end of the programme this number was 44 (four patients stayed in the open-ended programme); and at six months follow-up this number was 40 (since this is an ongoing study, three patients could not have had the follow-up measurement after six months). The mean (SD) length of the programme as 


\section{SFM Bouwens et al.}

provided by rehabilitation centre Blixembosch was 7.6 (3.8) months; the length of the programme as provided by rehabilitation centre Hoensbroeck was 5 months for each participant. The length of treatment between the two rehabilitation centres differed significantly $(F=58.4, t=3.3, \mathrm{df}=42$, $P<0.05)$. One patient, who was treated for the consequences of his traumatic brain injury, had a stroke between the end of the programme and six months follow-up. His level of functioning decreased due to this stroke and therefore original goals could not be measured reliably at six months follow-up. The goal attainment scaling score of this patient was excluded from the six months follow-up. Table 2 shows the patients' characteristics. More males than females participated in the study and the majority had had a stroke or a traumatic brain injury. The mean scores for the cognitive domains were all above cut-off. Most patients experienced problems on instrumental activities of daily life.

Table 3 shows a descriptive analysis of goal numbers and goal attainment scaling scores at each time point. When controlling for length of treatment, the change of goal attainment scaling scores between baseline and follow-up did not differ between the two rehabilitation centres $(P>0.05)$. The details of this analysis are described separately below.

\section{Number of goals and time required for setting the goals}

Forty-eight patients set 186 goals in total. The mean number of goals set for the patients was 4 (1), ranging from 2 to 6 . Four patients set two goals; these patients could not come up with more goals. It took less than 30 minutes to set these two goals for all four patients. The other 44 patients had three or more goals. It was possible to set at least three goals within 30 minutes for 24 of them. For 18 patients, the goal-setting procedure took between 30 and 45 minutes and in two cases it took 1 hour to set goals. Reasons for exceeding the 30-minute time-frame were: lack of insight, emotional and communication problems, problems with specifying goals and having more than three goals.
Table 2 Patient characteristics

\begin{tabular}{|c|c|}
\hline & Total group $N=48$ \\
\hline Age in years, mean (SD), range & $46.1(10.7), 23-67$ \\
\hline Male/female, number (\%) & $29(60) / 19(40)$ \\
\hline $\begin{array}{l}\text { Time since brain injury in years, } \\
\text { mean (SD), range }\end{array}$ & $2.1(3.0), 0-13$ \\
\hline \multicolumn{2}{|l|}{ Level of education, number (\%) } \\
\hline Low & $12(25)$ \\
\hline Medium & $19(40)$ \\
\hline High & $17(35)$ \\
\hline \multicolumn{2}{|l|}{ Cognitive functioning (mean (SD), range) } \\
\hline $\begin{array}{l}\text { Memory (AVLT, decile } 0-10 \text {, } \\
\text { cut-off }<2 \text { ) }\end{array}$ & $5.0(3.0)$ \\
\hline $\begin{array}{l}\text { Basal speed (TMT A, percentile 0-100, } \\
\text { cut-off }<5 \text { ) }\end{array}$ & $32.1(32.5)$ \\
\hline $\begin{array}{l}\text { Attention (D2, percentile } 0-100 \text {, } \\
\text { cut-off }<5 \text { ) }\end{array}$ & $38.8(34.0)$ \\
\hline \multicolumn{2}{|l|}{$\begin{array}{l}\text { Executive function (BADS, standard } \\
\text { score, cut-off -2) }\end{array}$} \\
\hline Zoo map & $-0.1(1.2)$ \\
\hline Rule shift & $-0.4(1.3)$ \\
\hline Six element test & $-0.3(1.3)$ \\
\hline Action plan test & $-0.2(1.8)$ \\
\hline $\begin{array}{l}\text { General intellectual functioning } \\
\text { (WAIS III, standard score, cut off }-2 \text { ) }\end{array}$ & $0.2(1.1)$ \\
\hline \multicolumn{2}{|l|}{$\begin{array}{l}\text { Everyday functioning (number of } \\
\text { patients experiencing problems } \\
\text { with IADL (\%)) }\end{array}$} \\
\hline Preparing a meal & $37(77)$ \\
\hline Shopping & $25(52)$ \\
\hline Telephone use & $38(79)$ \\
\hline $\begin{array}{l}\text { Activities with regard to mail, } \\
\text { appointments and finances }\end{array}$ & $43(90)$ \\
\hline \multicolumn{2}{|l|}{ Diagnosis (number (\%)) } \\
\hline Stroke & $15(31)$ \\
\hline Traumatic brain injury & $15(31)$ \\
\hline Subarachnoidal haemorrhage & $6(13)$ \\
\hline Brain tumour & $5(11)$ \\
\hline Epilepsy & $1(2)$ \\
\hline Viral infection & $2(4)$ \\
\hline Sinus thrombosis & $1(2)$ \\
\hline Hypoxia-induced brain injury & $2(4)$ \\
\hline Mixed type & $1(2)$ \\
\hline
\end{tabular}

AVLT, Auditory Verbal Learning Test; TMT A, part A of the Trail Making Test; BADS, Behavioural Assessment of Dysexecutive Syndrome; WAIS III, Wechsler Adult Intelligence Scale-III; IADL, instrumental activity of daily life.

\section{Domains included in the goals}

Goals were set in four general domains: cognition, emotion, behaviour and other. Table 4 shows the number of goals for each general domain and specific domain. Most goals were set in the cognitive domain. Memory and attention/concentration were the cognitive categories in which most goals 
were set, followed by strategy use and planning/ organizing. In the emotional domain, most goals were set for acceptance. Aggression/temper and fatigue were the behavioural domains mentioned most frequently.

\section{To what extent were goals realistic?}

The mean (SD) goal attainment scaling score at baseline for 48 patients was 32.4 (3.8). One week after the end of the programme this score was 51.4 (10.7) $(N=44)$. The mean goal attainment scaling score slightly increased at six months follow-up (52.5 (11.0) for 40 patients (Table 3)). Since both scores fall within the 40-60 range, it can be stated that goals on both measurements were realistic. The mean (SD) number of general domains covered by the goals per patient is 2 (1).

Table 3 Descriptive analysis of goal numbers and goal attainment scaling scores at each time point when used in people with acquired brain injury

Number of goals per patient

Number of general domains covered by the goals

Goal attainment score at baseline

Goal attainment score at the end of the programme $(N=44)$

Goal attainment score at six months follow-up $(N=40)$

Values are presented as mean (SD), range for a total group of 48 patients, unless stated otherwise.
Some goals were not attained because the goals changed along the way according to the patients. This was the case for 10 goals, divided over six patients. During cognitive rehabilitation, two of these patients had learned to cope with their problems in other ways than had been described in the goals in advance (viz. two patients had learned to focus on only one person during a conversation, while the goal was to follow a conversation of more than two people). At follow-up, these new coping styles could not be scored; therefore the predefined goal was not met. The other four patients found that the former goals were no longer an issue and that they had learned what was of real importance to them (e.g. one patient did not consider it any longer a problem if things did not go according to plan).

\section{Level of attainment}

Baseline data were complete for 48 patients, covering 186 goals; $44(24 \%)$ of these goals were set at the '-2' level and $142(76 \%)$ at the ' -1 ' level. Longitudinal data at one week after the end of the programme were complete for 44 patients, covering 169 goals; $118(70 \%)$ of these goals were attained $(47(28 \%)$ were attained, $63(37 \%)$ were higher than expected, and $8(5 \%)$ were much higher than expected), and $51(30 \%)$ of these goals were not attained $(37(22 \%)$ were lower than expected, and $(14(8 \%)$ were much lower than expected). Longitudinal data at six months follow-up were complete for 40 patients, covering

Table 4 Overview of content of domains in which goals were set

\begin{tabular}{|c|c|c|c|c|c|c|c|}
\hline Cognition & $N$ & Emotion & $N$ & Behaviour & $N$ & Other & $N$ \\
\hline Memory & 24 & Self-esteem & 2 & Impulsivity/inhibition & 4 & Work related & 4 \\
\hline Attention/concentration & 17 & Fear & 4 & Restless & 4 & $\begin{array}{l}\text { Education about } \\
\text { consequences acquired } \\
\text { brain injury }\end{array}$ & 6 \\
\hline Planning/organizing & 11 & Acceptance & 17 & Assertiveness & 9 & Peer support & 1 \\
\hline Structure & 5 & Mood & 3 & Aggression/temper & 11 & Physical & 1 \\
\hline Time pressure & 1 & Preoccupation & 1 & Social skills & 1 & Administration & 6 \\
\hline Strategy use & 14 & Deal with emotions & 1 & $\begin{array}{l}\text { Affective feelings } \\
\text { to others }\end{array}$ & 8 & & \\
\hline Dual tasking & 1 & Burden & 7 & Fatigue & 13 & & \\
\hline Flexibility & 3 & Enjoy life again & 2 & $\begin{array}{l}\text { Take some rest } \\
\text { Talkative } \\
\text { Making choices }\end{array}$ & $\begin{array}{l}3 \\
1 \\
1\end{array}$ & & \\
\hline Total & 76 & & 37 & & 55 & & 18 \\
\hline
\end{tabular}


155 goals; $112(72 \%)$ of these goals were attained $(47(30 \%)$ were attained, $48(31 \%)$ were higher than expected, and $17(11 \%)$ were much higher than expected), and 43 (28\%) of these goals were not attained (31 $(20 \%)$ were lower than expected, and $12(8 \%)$ were much lower than expected).

\section{Clinical experiences}

It took more time to set three goals in the first cases of the goal-setting procedure. After some practice, it became easier to set goals. Patients were asked to formulate goals in all 48 cases. The first reaction of many patients was that their goal was to become the person they had been before their brain injury. Since this goal is too broad and unrealistic in most cases, the clinical researcher had to explain to the patients that the goals had to be more specific.

Some patients had difficulties with the abstract nature of goal attainment scaling. By providing these patients with some examples of possible goals and using verbal explanations for the different levels (e.g. 'much higher than expected') instead of scores (e.g. '-2'), they all understood the goal-setting procedure. In most cases $(n=33)$ the clinical researcher was alone with the patient when setting goals. In the other 15 cases, the caregiver was present.

In two cases, the caregiver came up with goals important for the relationship, such as affection and sharing opinions. In these cases, we consulted both the caregiver and the patient before deciding to include the goals suggested by the caregiver. During the follow-up measures, the clinical researcher asked the patient's permission to also discuss the level of attainment of the goals suggested by the caregiver with the caregiver.

In two cases, the caregiver helped the clinical researcher in persuading the patient to set realistic goals and to motivate the patient to think of what he or she wanted to attain. Four cases lacked insight into their problems. Although the clinical researcher discussed lack of insight with three of them, they still wanted to set an unrealistic goal as a test to see if they could not do the things they could do before. The unrealistic level was set at +1 or +2 and the expected level was set at ' 0 '. The fourth person denied all problems. After some discussion about daily life functioning with the clinical researcher and the caregiver, this patient formulated three goals.

Besides some difficulties in setting goals with patients, we also experienced difficulties in measuring the attainment of goals with two patients. During a phone call these patients were asked to what extent they thought their goals had been met. The clinical researcher read the possibilities out loud. One patient mentioned that he found it difficult to indicate the level attained, since the descriptions were too abstract for him.

One patient was depressed at follow-up. She recognized that her depression could have influenced the outcome. She was negative about herself at the time of follow-up. In some cases, setting goals was confronting. Thinking about the things the patients had to change or adapt made them realize that things were going differently now. For some people this idea was motivating, while for others, this was disappointing.

\section{Discussion}

It proved possible to set three goals within an acceptable time-frame, to involve patients in the goal-setting procedure, to set realistic goals, and to set goals within relevant domains. We discovered that setting goals is difficult when patients have insufficient insight into their problems, experience emotional and communication problems or have difficulty specifying goals. Measuring the level of attainment is problematic when comorbidity occurs in between the measurements; when patients have mood problems like depression; and when goals change along the way.

The strength of our study lies in the relatively large sample size. Only the study by Rockwood et $a .^{15}$ had a comparable sample size. Furthermore, we tested the feasibility of, and clinical experiences with goal attainment scaling in this population using well-defined feasibility aspects and the person who set the goals and assessed the level of attainment was not involved in the cognitive rehabilitation programmes. This procedure ensures independent assessment of the levels attained. In most studies goals were set and 
the level of attainment was assessed by the treatment team itself or by an independent researcher who discussed level of attainment with the treatment team. The clinical researcher in our study did not discuss with the treatment team what goals were set and what level was attained. Instead she directly asked the patient what goals the patient wanted to attain and what level was attained. The clinical researcher was familiar with the content of the rehabilitation programme and with setting goals. By providing the rehabilitation team with the goals it was ensured that the team knew the goals as well.

Some other studies that used goal attainment scaling as a method for measuring outcome scored the follow-up measurements by phone as well. ${ }^{22,23}$ This approach, however, slightly differs from most studies in which level of attainment is scored after observation of the patient by the rehabilitation team or the assessor. A disadvantage of follow-up by phone is the fact that it is impossible to see non-verbal cues. Moreover, people may feel uncomfortable when they have to discuss personal topics by phone without seeing the clinical researcher. An advantage of the use of the phone is that is it time effective. Our experience was that most patients understood the procedure and were able to report their level of functioning during a phone call. Furthermore, the nature of most goals set did not allow direct observation (e.g. level of acceptance). Therefore, it was not necessary to actually see the patients. By formulating the levels of attainment in a clear manner at baseline, it was possible for the researcher to assess level of attainment by phone. When goals have an observable nature, such as number of metres that a person can walk after an intervention, it is not possible to do the followup assessment by phone.

The patient reported the level of attainment. Therefore, it was possible for patients to provide socially desirable answers that did not reflect their actual level of attainment. However, as most levels of attainment could not be observed, the best way to assess level of attainment is by asking the patient.
The goal-setter has to be sure that the goals set by the individual do not go beyond the scope of the research or clinical intervention. So, to a certain extent, the goal-setter has to guide the patient. This guidance makes goal attainment scaling an interactive approach that requires clinical skills, like being able to confront patients when they choose unrealistic goals or lack insight into their problems. For clinical purposes, this interactive process is part of the intervention. For the purpose of research, however, this interactive process before the intervention has started may influence the actual intervention.

For some patients, confronting them with their unrealistic goals enhanced their insight into their problems. This aspect is relevant for clinical practice but not for research purposes; the goal-setting procedure in the case of patients who lack insight is an interactive, therapeutic process that influences the actual research intervention.

Moreover, goals could be set with the patient alone. The assistance of the caregiver might be helpful when the patient cannot formulate any goal. When caregivers have specific wishes or needs, separate caregiver goals or system goals can be set as well.

Goal attainment scaling is an individualized approach and based on the needs of the patient. This individualized aspect is the strong point of the method and provides information about the level of satisfaction of the patient. As we have found in our study, however, some patients reported that they were satisfied with their level of functioning after the programme although they did not attain their predefined goals. Therefore, in clinical practice, goal attainment scaling is recommended for use as complementary to and not as a replacement for other instruments. In research, goal attainment scaling should be compared with traditional standardized measures, such as the Frenchay Activities Index ${ }^{24}$ and the Stroke-Adapted Sickness Impact Profile. $^{25}$

Although goal attainment scaling is an interesting method for both clinical and research aims, it is not yet well understood and has recently started to be used in settings other than psychiatry. 
Several aspects need to be taken into account by those who consider using it. With regard to the goal-setting procedure, goal-setters must be aware of the patient's emotional status, level of insight, communication skills and capacity to specify goals. With respect to the level of attainment, it is important to identify possible depression and comorbidity.

It requires practice and clinical skills to learn to apply goal attainment scaling. We recommend practising the goal-setting procedure before actually using it. It pays off to invest in the proper training of staff and the result is a useful tool.

Hurn et $a l .{ }^{26}$ reviewed the literature on clinimetric aspects of goal attainment scaling when used as measure of outcome by clinicians working with patients in physical and neurological rehabilitation settings. They found strong evidence for the reliability, validity and sensitivity of goal attainment scaling. Our study adds relevant information on its practical use. We recommend goal attainment scaling for use in clinical practice when measuring clinical change. As goal attainment scaling reflects individual needs, it can be useful for quality of life as well.

\section{Clinical messages}

- Goal attainment scaling is useful as a clinical tool for assessing the outcome of cognitive rehabilitation for people with acquired brain injury

- Goal attainment scaling is less feasible when patients lack insight or have mood problems.

\section{Acknowledgements}

We would like to thank Carlijn van den Boomen, Danny Mennen and Gisela Claessens for their assistance in data collection and data processing. We would particularly like to thank Professor Lynne Turner-Stokes for her comments on an earlier version of this article.

\section{References}

1 Ettenhofer ML, Abeles N. The significance of mild traumatic brain injury to cognition and self-reported symptoms in long-term recovery from injury. J Clin Exp Neuropsychol 2008; 11: 1-10.

2 Greenwood R. The consequences of brain injury: classification assessment of outcome. Neuropsychol Rehabil 1999; 9: 231-40.

3 Sohlberg MM, Mateer CA. Cognitive rehabilitation: an integrative neuropsychological approach. The Guilford Press, 2001.

4 National Institutes of Health. NIH consensus statement: Rehabilitation of persons with traumatic brain injury. NIH, 1998.

5 Prigatano GP. Principles of neuropsychological rehabilitation. Oxford University Press, 1999.

6 Wilson BA. Neuropsychological rehabilitation. Annu Rev Clin Psychol 2008; 4: 141-62.

7 Ben-Yishay Y, Prigatano GP. Cognitive remediation. In Rosenthal M, Griffith ER, Bond MR, Miller JD. eds. Rehabilitation of the adult and child with traumatic brain injury. FA Davis, 1990, 393-400.

8 Kiresuk T, Sherman RE. Goal attainment scaling: a general method for evaluating comprehensive community mental health programs. Community Ment Health J 1968; 4: 443-53.

9 Malec JF. Goal attainment scaling in rehabilitation. Neuropsychol Rehabil 1999; 9: $253-75$.

10 Joyce BM, Rockwood KJ, Mate-Kole CC. Use of goal attainment scaling in brain injury in a rehabilitation hospital. Am J Phys Med Rehabil 1994; 73: 10-14.

11 Fisher K. Assessing clinically meaningful change following a programme for managing chronic pain. Clin Rehabil 2008; 22: 252-59.

12 World Health Organization. International classification of functioning, disability and health. WHO, 2001.

13 Goodyear DL, Bitter JA. Goal attainment scaling as a program evaluation measure in rehabilitation. J Appl Counsel 1974; 5: 19.

14 Lannin N. Goal attainment scaling allows program evaluation of a home-based occupational therapy program. Occup Ther Health Care 2003; 17: 43-54.

15 Rockwood K, Joyce B, Stolee P. Use of goal attainment scaling in measuring clinically important change in cognitive rehabilitation patients. J Clin Epidemiol 1997; 50: 581-88. 
16 Bouwens SFM, van Heugten CM, Verhey FRJ. Review of goal attainment scaling as a useful outcome measure in psychogeriatric patients with cognitive disorders. Dement Geriatr Cogn Disord 2008; 26: 528-40.

17 Rey A. L'examen clinique en psychologie [The clinical examination in psychology]. Presses Universitaires de France, 1958.

18 Reitan R. Trail Making test: Manual for administration, scoring, and interpretation. Indiana University, 1956.

19 Brickenkamp R. Aufmerksamkeits-BelastungsTest (test d2). [The d2 test of attention]. Hogrefe, 1962.

20 Wilson BA, Alderman N, Burgess PW, Emslie H, Evans JJ. Behavioural Assessment of the Dysexecutive Syndrome (BADS). Thames Valley Test Company, 1996.

21 Wechsler D. Wechsler Adult Intelligence Scale-III. The Psychological Corporation, 1997.

22 Stuifbergen AK, Becker H, Blozis S, Timmerman G, Kullberg V. A randomized clinical trial of a wellness intervention for women with multiple sclerosis. Arch Phys Med Rehabil 2003; 84: 467-76.

23 Stuifbergen AK, Becker H, Timmerman GM, Kullberg V. The use of individualized goal setting to facilitate behavior change in women with multiple sclerosis. $J$ Neurosci Nurs 2003; 35: 94-99, 106.

24 Schuling J, de Haan R, Limburg M, Groenier KH. The Frenchay Activities Index. Assessment of functional status in stroke patients. Stroke 1993; 24: 1173-77.

25 van Straten A, de Haan RJ, Limburg M, Schuling J, Bossuyt PM, van den Bos GA. A stroke-adapted 30-item version of the Sickness Impact Profile to assess quality of life (SA-SIP30). Stroke 1997; 28: $2155-61$.

26 Hurn J, Kneebone I, Cropley M. Goal setting as an outcome measure: A systematic review. Clin Rehabil 2006; 20: 756-72.

27 Malec JF, Smigielski JS, DePompolo RW. Goal attainment scaling and outcome measurement in postacute brain injury rehabilitation. Arch Phys Med Rehabil 1991; 72: 138-43.

28 Gordon JE, Powell C, Rockwood K. Goal attainment scaling as a measure of clinically important change in nursing-home patients. Age Ageing 1999; 28: 275-81.

\section{Appendix 1 - Description of goal attainment scaling}

The goal attainment scaling method consists of a six-step process. To select the goals that are relevant to the individual patient in step 1 the patient and/or caregiver is either interviewed by a clinician to identify problem areas and to determine goals for those areas in which intervention is planned. Team members can also set goals themselves after interviewing the patient and/or caregiver about problem areas. When goal attainment scaling is used for research to test the effect of an intervention, the setting of goals by a clinical researcher who is not involved in the intervention is recommended. To ensure reliable calculation with a standard formula, a minimum of three goals is recommended. ${ }^{27}$

Step 2 is optional. It provides the opportunity to weight the goals. Several methods exist to do so. We set all weights at 1 .

In Step 3 a follow-up time period before the start of the evaluation is determined, at which point the clinician will measure the level of goal attainment.

In step 4 the expected outcome, i.e. the goal, is set. Outcome levels are specified in observable terms in such a way that laymen are able to score the follow-up guides (Table 1). Levels do not overlap. The expected outcome is scored with ' 0 '.

Step 5 consists of completion of the other scale levels, using possible outcomes including much less than expected $(-2)$, somewhat less than expected $(-1)$, somewhat better than expected $(+1)$ and much better than expected $(+2)$.

In step 6, goal attainment scaling baseline levels are noted on the follow-up guide. If a clinically relevant deterioration is plausible, the description of the current status can be scored as ' -1 ,' with the worsened state scored as ' -2 .' If the problem is at its worst, the current level of functioning is scored as ' -2 .'

Patients receive an intervention and at the defined follow-up time (e.g. end of intervention), the patient is scored at the attained level. 
The overall goal attainment scaling score at baseline and follow-up is calculated with a standard formula (Appendix 2). The formula produces an overall score that is an average of the outcome scores, adjusted for the relative weighting assigned to goals, the varying number of goals, and the expected inter-correlation among the goal scales.

The hypothetical mean goal attainment scaling score at follow-up is $50(\mathrm{SD}=10)$; consistently high or low follow-up scores indicate that goals were too easy (scores $>50$ ) or too difficult to attain (scores <50). ${ }^{28} \mathrm{~A}$ goal attainment scaling score at follow-up of 50 indicates that all predefined goals met the expected outcome at follow-up.

\section{Appendix 2 - Formula to calculate the goal attainment scaling scores}

$$
\begin{aligned}
& \text { Goal attainment scaling score } \\
& =\frac{50+10 \sum\left(w_{i} x_{i}\right)}{\sqrt{\left(0.7 \sum w_{i}^{2}+0.3\left(\sum w_{i}\right)^{2}\right)}}
\end{aligned}
$$

where $x_{i}$ is the attainment level and $w_{i}$ is the weight assigned to the goal area. Because the expected outcome/programme goal is assigned the score of 0 , if all goals are met, the outcome score would be 50 . 